\title{
STUDIUL MICROSCOPIC AL TRIHOMILOR GLANDULARI ȘI NON-GLANDULARI LA GENOTIPURI DE LAVANDULA ANGUSTIFOLIA MILL. sSp. ANGUSTIFOLIA
}

\author{
Calalb $^{l}$ T., Fursenco ${ }^{l}$ C., Gonceariuc ${ }^{2}$ M., Butnăraș ${ }^{2} V$. \\ ${ }^{I}$ Universitatea de Stat de Medicină și Farmacie "Nicolae Testemițanu", \\ ${ }^{2}$ Institutul de Genetică, Fiziologie și Protecție a Plantelor, Chișinău, Republica Moldova \\ tatiana.calalb@usmf.md
}

\begin{abstract}
The microscopic and citochemistry study denotes 3 types of glandular trichomes (peltate, capitates type I and type II), implicated in the synthesis of the metabolites, including volatile oils (with biological and protective role) and one type of non-glandular trichomes with the potential adaptive role to stressors in 7 new genotypes (4 cultivars - Moldoveanca 4, Vis Magic 10, Alba 7, Aroma Unica and 3 hybrids - Fr.5S8-24, Fr.8-5-15V and Cr.13S-6-7) of sp. Lavandula angustifolia Mill., spp. angustifolia. The degree of development and distribution mode of both types of trichomes
\end{abstract}


(glandular and non-glandular) varies according organs (stem, leaf, bract, flower calyx and corolla) and genotype.

Keywords: Lavandula angustifolia, genotype, hybrid, variety microscopy, non-glandular trichomes, glandular trichomes.

\section{Introducere}

Un număr extins de plante angiosperme dezvoltă trihomi cu multiple funcții pe suprafețele organelor. Trihomilor non-glandulari li se atribuie funcția de protecție [9], astfel conferindu-le un rol important în adaptarea plantelor la condițiile climatice nefavorabile. În trihomii glandulari are loc biosinteza şi acumularea diferitor amestecuri de metaboliţi primari şi secundari (alcaloizi, uleiuri volatile, carbohidrați) cu rol biologic (procesele de polenizare și protecție) [7] și aplicativ în farmacie, medicină, cosmetică, alimentație și biopesticide.

Specia Lavandula angustifolia Mill, subspecia angustifolia, cultivată și în Republica Moldova, este cunoscută ca sursă de materie primă naturală, bogată în ulei volatil cu diverse efecte terapeutice: antiseptic, antimicrobian, antifungic, sedativ, analgezic, cicatrizant, antiinflamator, carminativ, hipotensiv, antioxidant etc. Cantitatea și calitatea uleiului esențial $[8,13]$ corelează cu condițiile pedo-climatice de creștere ale plantelor, care în ultimii ani sunt instabile și imprevizibile. Este necesară ameliorarea genetică a speciei prin crearea noilor genotipuri de levănțică cu potențial structural adaptiv la acțiunea factorilor stresogeni și condițiile climatice nefavorabile de creștere. Astfel, sunt foarte oportune studiile complexe, interdisciplinare, inclusiv prin metode microscopice, ale noilor genotipuri de levănțică, create în Laboratorul Plante Aromate și Medicinale a IP IGFPP [6] pentru identificarea celor de perspectivă prin determinarea potențialului structural adaptiv și de acumulare a metaboliților secundari, inclusiv a celor de natură terpenică.

\section{Materiale și metode}

În calitate de material biologic au servit plantele de la 7 genotipuri de levănțică cu diferită perioadă de maturizare (timpurie, medie și tardivă): soiuri de provenienţă hibridă (hibrizi $F_{1}$ ) - Alba 7, Aroma Unica, Moldoveanca 4, Vis Magic 10 şi hibrizi $F_{1}$ - Fr.5S8-24, Fr.8-5-15V și Cr.13S-6-7 [6]. Studiul microscopic a fost efectuat pe secțiuni transversale și micropreparate superficiale din material javelizat al tulpinii, frunzei, bracteei și florii, analizate în microscopul Micros cu cameră digitală, cuplată la computer. Membranele celulozice și lignificate au fost identificate prin aplicarea soluției de Cl-Zn-I şi Albastru de metilen. Conţinutul lipidic și membranele suberificate sau cutinizate - cu reagentul chimic Sudan III.

\section{Rezultate și discuții}

Analiza secțiunilor transversale și a micropreparatelor superficiale din material javelizat la 7 genotipuri de levănțică denotă prezența a 2 categorii de trihomi: non-glandulari și glandulari.

Trihomi non-glandulari. Acest tip de trihomi au fost identificaţi la toate genotipurile studiate, dar cu diferit grad de ramificație și densitate pe unitate de suprafață pe tulpini, frunze, bractei, caliciul și corola florii. Trihomii non-glandulari sunt pluricelulari, din 3-11 celule alungite, aranjate în ramificații anostomozate de nivelul I (frecvent cu 2 terminații bifurcați) și nivelele 2-4 (rar 5) cu mai multe (5-8) terminații dispuse verticilat. Aceştea constau dintr-o celulă bazală cu pereții celulari îngroșați, relativ mai mare și poziționată mai sus față de celelalte celule epidermale, pe care se dezvoltă o celulă, alungită, orientată perpendicular în raport cu suprafața epidermei și are aspectul unui pilon, de unde pornesc 
ramificațiile, care gradual se îngustează, etajate în mai multe nivele (1-4). Astfel, trihomii formează o rețea deasă, constituită din intercalațiile ramificațiilor diferitor nivele. Celulele trihomilor au lumenul celular micșorat, iar pereții celulozici sunt îngroșaţi, bine evidențiați (colorați cu Albastru de metilen și soluție Cl-Zn-I), uneori suberificați (se colorează în roșu la aplicarea reagentului Sudan III), îndeosebi ale celulei pilon şi celulelor I nivel de ramificații. Relieful trihomilor non-glandulari reprezintă conform lucrărilor lui Werker E. [13] un indicator al etapei de dezvoltare. La trihomii juvenili suprafața perilor este netedă, iar la cei maturi - verucoasă. În luna aprilie a perioadei de vegetație a plantelor se observă formarea noilor trihomi non-glandulari cu rol în protecția plantelor la acțiunea excesivă a radiației, insolației, supraîncălzirii și diminuării pierderii umidității. Totodată, menționăm și prezența trihomilor verucoși (mai puțini) pe frunzele juvenile. Numărul trihomilor non-glandulari este în creștere până la maturarea frunzelor, care coincide cu perioada de înflorire în masă, ulterior, lumenul celulelor se reduce la maxim, trihomii pierd treptat vitalitatea și pot cădea. La toate genotipurile analizate pubescența este mai accentuată pe partea abaxială a frunzei și bracteei, partea externă a sepalelor caliciului, în special, de-a lungul nervurilor.

Gradul de pubescență și ramificație a trihomilor, grosimea pereților celulari și relieful suprafeței trihomilor corelează cu tipul genotipului. S-a evidențiat că plantele la soiurile: Aroma Unica au o pubescență densă din trihomi lungi și cu 3-4 nivele de ramificații; Alba 7 ramificațiile trihomilor lungi cu suprafață verucoasă și aspect albicios; Vis Magic 10 preponderent trihomi cu ramificații de ordinul 3-4, celulele cu pereții suberificați și verucoși; Moldoveanca 4 - prevalează trihomii bifurcați cu suprafața moderat verucoasă, iar la hibrizi: Fr8-5-15V - pubescență abundentă din trihomi groși cu suprafața verucoasă; Fr 5S8-24 trihomi bifurcați; Cr.13S-6-35 - mulți trihomi ramificații cu terminații înguste.

Trihomi glandulari. La toate genotipurile de levănţică analizate au fost descrise 3 tipuri de trihomi glandulari: glandulari peltați și glandulari capitați de tipul I și tipul II.

Trihomi glandulari peltați. Acești trihomi peltați se dezvoltă pe: epiderma tulpinii, ambele epiderme ale frunzei și bracteelor (prevalează pe cea abaxială), epidermele sepalelor caliciului și petalelor corolei florii. Ei sunt distribuiți aproape uniform pe suprafața dintre nervurile epidermei la frunză, poziționați sub ramificațiile trihomilor non-glandulari, care formează un ecran dens și sigur de protecție. Dezvoltarea din abundență și expresia morfologică densă a trihomilor non-glandulari prezintă un impediment pentru vizualizarea trihomilor glandulari peltați, îndeosebi, pe preparatele superficiale. Trihomii glandulari peltaţi, în secțiune transversală, constau dintr-o celulă bazală înglobată între celulele epidermale, un picioruş scurt și o glandă sferiformă. În glanda, vizualizată deasupra, se disting 8 celule secretoare, aranjate într-un plan radial de la picioruș. Între celulele secretoare ale glandei și cuticulă este un spațiu mare - cameră subcuticulară, unde substanțele elaborate se acumulează. Pe frunzele juvenile majoritatea trihomilor peltați au spațiu subcuticular plin cu multe vezicule mici lipidice (identificate cu Sudan III), dar pe cele mature, deseori, se obsevă o globulă voluminoasă (formată la contopirrea veziculelor mici)și câteva mici, la fel de natură lipidică.

Pe parcursul dezvoltării frunzelor are loc creșterea numărului de trihomi peltați și extensia volumului glandei, dimesiunile maxime revenind frunzelor mature, care corespund perioadei de înflorire a plantelor. Rezultate similare au fost relatate și în alte lucrări științifice $[2,3]$. Pe micropreparate au fost observați și trihomi peltați degerativi (degradativi), la care cuticula s-a erupt, iar conținutul a fost expulzat în exterior, în special, pe frunzele mature, menționați și în alte lucrări $[1,5]$. Conform studiilor, bazate pe metode de microscopie optică și electronică, combinate cu citoreacții specifice $[4,8,12]$, trihomii glandulari peltați sunt specializați doar în biosinteza și acumularea substanțelor lipidice, în special, al terpenelor. 
Prin studii electronomicroscopice a fost elucidat mecanismul de sinteză și secreție al uleiurilor volatile [5, 12]. Un studiu mai recent [15] susţine, că plastidele sunt organitele cele mai implicate în biosinteza uleiurilor volatile, urmate de reticulul endoplasmatic [13], care, totuşi, cu vacuolele sunt considerate mai mult implicate în transportul uleiurilor volatile $[8,10,11$, 12]. Exocitoza cu vectorul mural este mecanismul verosimil de transport al uleiurilor volatile din celule în spaţiul subcuticular [8].

Trihomi glandulari capitați sunt de 2 tipuri, care diferă prin morfologie și dimensiuni: tipul I - glandulari capitaţi cu glanda uni- sau bicelulară și picioruş scurt unicelular și tipul II - glandular cu glanda dintr-o singură celulă, dar piciorușul pluricelular și foarte lung.

Trihomii glandulari capitați de tipul I constau din glanda sferiformă, mică, din 1-2 celule și picioruşul unicelular și scurt, care sunt dificil de observat din motivul dimensiunilor mici și abundenței de trihomi non-glandulari. Totuși, la analiza multiplelor micropreparate superficiale și pe secțiuni transversale ale tulpinii, frunzei, bracteei, caliciului și corolei, acești trihomi pot fi identificați. Spaţiul subcuticular (dintre celula secretoare și cuticulă) este mic, iar conținutul acumulat se presupune [8] că se evacuează în exterior nu prin eruperea cuticulei, dar prin intermediul microporilor. Unele studii susțin [16] că trihomii glandulari capitați de tipul I nu sunt implicați în biosinteza uleiurilor volatile, altele [1, 14] consideră că ei sunt specializați în elaborarea polizaharidelor și doar cu o cotă parte mică - în a sintezei uleiurlor volatile. Conform rezultatelor studiilor utramicroscopice [8] dictiozomii sunt organitele responsabile de biosinteza polizaharidelor, iar transportul este asigurat via veziculelor derivate de la dictiozomi cu vectorul celular mural, astfel contribuind la îmbogăţirea membranei plasmatice și asigurând evacuarea lor în spațiul subcuticular, la fel, prin exocitoză.

Trihomi glandulari capitați de tipul II au glanda dintr-o singură celulă, dar picioruşul foarte lung, pluricelular din celule alungite (diametrul mare depășește mai mult de 10 ori pe cel mic), iar ultima celulă a acestuia, pe care se dezvoltă celula glandei, este isodiametrică cu pereții celulari îngroșați, diametrul mai mic, decât celelalte celule ale piciorușului, ce induce aspect de gâtuitură. Relieful suprafeței de-a lungul piciorușului este ondulat, iar spre apex - doar verucos. Acest tip de trihomi au fost observaţi doar în grupuri (mănunchiuri), și doar în tubul intern al corolei la toate genotipurile studiate, inducând rolul lor în atragerea polenizatorilor. Astfel de trihomi au fost menționați și în alte studii știinţifice, ca o caracteristică pentru unele specii din fam. Lamiaceae [14], iar ulterior Zuzarte M. și colaboratorii prin microscopia electronică cu baleaj îi descrie la florile speciei L. pedunculata (Mill.) Cav [16]. În cazul studiului dat, la genotipurile noi de levănțică analizate, acești trihomi sunt mult mai lungi și la aplicarea reactivului Sudan III, glanda acestora prezintă o colorație roz-roșu, indicând natura lipidică, iar în alte lucrări [16] a fost detectat, atât conținutul total lipidic prin aplicarea reagenților Sudan roșu și Sudan negru, cât și conținutul lipidelor neutre cu reagentul Nile Blue.

Astfel, analizând datele obținute pentru trihomii glandulari peltaţi cu glanda din 8 celule secretoare prin prisma literaturii din domeniul de cercetare, constatăm, că rezultatele sunt aproape similare cu cele raportate pentru speciile L. pinnata L. [8], L. pedunculata (Mill.) Cav [16], Salvia officinalis L. [5], Mentha arvensis L. [11, 12] și diferite de specia Orthosiphon labiatus N.E.Br. [2], unde glanda trihomilor peltați constă, doar din 4 celule secretoare.

Trihomii glandulari capitați de tipul I au fost menționați la multe specii din familia Lamiaceae [1, 2, 3, 4, 5], iar cei de tipul II doar la specia L. pedunculata (Mill.) Cav [16]. Studiile microscopice la nivel celular și subcelular demonstrează implicarea diferențiată și specializată în concordanță cu tipul morfologic al trihomilor glandulari (peltați, capitați de 
gradul I și gradul II) în biosinteza și elaborarea metaboliților secundari (lipide totale/neutre, carbohidrați - pectine, zaharuri) $[4,8,11,12,14,15,16]$.

\section{Concluzii}

1. Trihomii non-glandulari cu rol de protecție la acțiunea factorilor nefavorabili se dezvoltă pe toate organele (tulpină, frunză, bractee, caliciul și corola florii) supraterane ale plantelor la toate genotipurile studiate, dar aspectul morfologic (numărul de nivele, gradul de ramificaţie, lungimea/grosimea ramificațiilor) și gradul de pubescență corelează cu tipul organului și variază de la genotip la genotip.

2. Au fost identificate și descrise 2 categorii de trihomi glandulari: peltați (cu picioruș scurt şi glanda din 8 celule secretoare) și capitați, ultimii fiind de tipul I (picioruş scurt și glanda uni- sau bicelulară) cu distribuție solitară pe toate organele supraterane și de tipul II (picioruş pluricelular, foarte lung cu gâtuitură și glanda unicelulară) dezvoltați în grupuri în tubul corolei. Trihomii glandulari au o implicare diferențiată în biosinteza metaboliților secundari, care corelează cu tipul morfologic.

\section{Bibliografe}

1. Ascensao L, Mota L, Castro M. Glandular trichomes on the leaves and flowers of Plectranthus ornatus: morphology and histochemistry. Annals of Botany. 1999;84:437-447.

2. Bhatt A, Naidoo Y, Nicholas A. An investigation of the glandular and non-glandular foliar trichomes of Orthosiphon labiatus N.E.Br. [Lamiaceae]. New Zealand Journal of Botany. 2010;48(4):153-161.

3. Bourett TM, Howard RJ, O'keefe DP, Hallahan DL. Gland development on leaf surfaces of Nepeta racemosa. Int. J. Plant. Sci. 1994;155:623-632.

4. Clark R, Hamilton J, Chapman J, Rhodes M, Hallanhan D. Analysis of monoterpenoids in glandular trichomes of catmint Nepeta racemosa. Plant J. 1997;11:1387-1393.

5. Corsil G, Bottega S. Glandular hairs of Salvia officinalis: New data on morphology, localization and histochemistry in relation to function. Ann. Bot. 1999;84:657-664.

6. Gonceariuc M. Lavanda. Chișinău: Tipog. "Print-Caro"; 2018;131 p. ISBN 978-9975-56541-7.

7. Glas J, Bernardus C, Schimmel B, Schuurink R, et al. Plant glandular trichomes as targets for breeding or engineering of resistance to herbivores. Int. J. Mol. Sci. 2012;13:1707717103.

8. Huang SH, Kirchoff B, Liao J. The capitate and peltate glandular trichomes of Lavandula pinnata L. (Lamiaceae): histochemistry, ultrastructure, and secretion. J. of the Torrey Botanical Society. 2008;135:155-167.

9. Klich MG. Leaf variations in Elaeagnus angustifolia related to environmental heterogeneity. Environment and Experimental Botany. 2000;44:171-183.

10. Machado SR, Grego'Rio EA, Guimara es E. Ovary peltate trichomes of Zeyheria montana (Bignoniaceae): Developmental ultrastructure and secretion in relation to function. Ann. Bot. 2006;97:357-369.

11. Turner G, Croteau R. Organization of monoterpene biosynthesis in Mentha. Immunocytochemical localizations of geranyl diphosphate synthase, limonene-6hydroxylase, isopiperitenol dehydrogenase, and pulegone reductase. Plant Physiol. 2004;136:4215-4227.

12. Turner G, Gershenzon J, Croteau R. Development of peltate glandular trichomes of Peppermint. Plant Physiol. 2000;124:665-679.

13. Valkama E, Salminen JP, Koricheva J, Pihlaja K. Comparative analysis of leaf trichome structure and composition of epicuticular flavonoids in Finnis Birch species. Ann. Bot. 2003;91:643-655. 
14. Werker E, Ravid U, Putievsky E. Structure of glandular hairs and identification of the main components of their secreted material in some species of the Labiatae. Isr. J. Bot. 1985;34:3145.

15. Zheng B, Yu L, Xing S, Wang F. Ultrastructure of the secretion of peltate glandular hairs in Ocimum basilium L. Bull. Bot. Res. 2002;22:176-180.

16. Zuzartea M, Dinisa A, Cavaleirob C, et al. Trichomes, essential oils and in vitro propagation of Lavandula pedunculata (Lamiaceae). Industrial Crops and Products. 2010;32: $580-587$. 